appear to fall into the transitional state, the early stage of which has been described as pre-pernicious anaemia and the later stage as latent pernicious anaemia (Wood, Cowling, Ungar, and Gray, 1960).

The evolution of gastric atrophy to latent pernicious anaemia has been described by Wood et al. (1960), but it is not known whether gastric atrophy invariably progresses to this stage. The transformation of latent into clinical pernicious anaemia is believed to depend on the individual's body stores of vitamin $B_{12}$ and on external precipitating factors, such as infection. The fact that achlorhydria was so often found in those of our patients whose absorption of vitamin $B_{12}$ was normal suggests that the patients with latent pernicious anaemia may have had a pre-existing simple atrophic gastritis.

The significance of gastric atrophy in iron-deficiency anaemia is not certain. It has been held that the gastric mucosal changes are the result of iron deficiency (Davidson and Markson, 1955 ; Badenoch et al., 1957). Against this view is the rarity of achlorhydria in the chronic iron-deficiency anaemia of hookworm infestation (Foy and Kondi, 1960 ; Ball, personal communication) and the finding that gastric atrophy, when it does occur, is not reversed by the administration of iron (Lees and Rosenthal, 1958).

Coghill (1960) has shown that atrophic gastritis is more common in those patients with iron-deficiency anaemia in whom there is no evidence either of blood loss or of exceptionally deficient iron intake. This "idiopathic" gastric atrophy appears to be genetically determined. It is most common in the Northern European races and rare in equatorial Africa. It is often a prelude to the development of pernicious anaemia. The combination of iron deficiency and the PatersonKelly syndrome is not found in a population unaffected by gastric atrophy. In patients with gastric atrophy, however, the Paterson-Kelly syndrome may appear either before there is any anaemia or after the gastric atrophy has led to the development of latent pernicious anaemia or iron-deficiency anaemia. Dysphagia may occur in patients with uncomplicated pernicious anaemia, so that iron deficiency does not appear to be essential to its development.

\section{Summary}

An investigation of 55 cases of the Paterson-Kelly syndrome showed a high incidence of iron deficiency, achlorhydria, and subnormal vitamin- $\mathrm{B}_{12}$ absorption.

It is suggested that this syndrome is associated with the genetically determined gastric atrophy found in patients with pernicious anaemia and that iron deficiency is a secondary feature.

We are indebted to the staff of the Cardiff Royal Infirmary, who have allowed us to investigate patients under their care, and to Professor H. Scarborough for his helpful criticism. One of us (A. J.) is in receipt of a grant from the Endowment Fund of the United Cardiff Hospitals.

\section{REFERENCES}

Ahlbom, H. E. (1936). Brit. med. F., 2, 331.

Badenoch, J., Evans, J. R., and Richards, W. C. D. (1957). Brit. 3. Haemat., 3, 175 .

Bock, O. A. A., Richards, W. C. D., and Witts, L. J. (1963). Gut, 4, 112. Coghill, N. F. (1960). Postgrad. med. f., 36, 733 .

Correia, J. P., and de Moura, M. C. (1963). Brit. med. F., 1, 365.

Correia, J. P., and de Moura, M. C. (1963). Brit. med. F., 1, 365.

Dacie, J. V. (1956). Practical Haematology, 2nd ed. Churchill, Lon

Foy, H., and Kondi, A. (1960). Trans. roy. Soc. trop. Med. Hyg., 54, 419.

Jacobs, A. (1962). Brit. med. f., 2, 91.

(1963). Ibid., 1, 1711 .

Joske, R. A., Finckh, E. S., and Wood, I. J. (1955). Quart. F. Med., 24,

Kelly, A. B. (1919). F. Laryng., 34, 285.

Kirchenberger, W., and Flett, R. L. (1946). Ibid., 61, 396.

Lees, F., and Rosenthal, F. D. (1958). Quart. F. Med., 27, 19.

McNab Jones, R. F. (1961). f. Laryng., 75, 529.

Moersch, H. J., and Conner, H. M. (1926). Arch. Otolaryng., 4, 112.

Mollin, D. L., Booth, C. C., and Baker, S. J. (1957). Brit. F. Haemut.. 3,412 .

Paterson, D. R. (1919). f. Laryng., 34, 289.

Ramsay, W. N. M. (1957). Clin. chim. Acta, 2, 214.

Schilling, R. F. (1953). f. Lab. clin. Med., 42, 860.

Smiley, T. B., McDowell, R. F. C., and Costello, W. T. (1963). Lance!, 2,7 .

Trowell, H. C. (1960). Non-infective Disease in Africa. Arnold, London. Vinson, P. P. (1922). Minn. Med., 5, 107.

Waldenström, J., and Hallen, L. (1938). Acta med. scand., Suppl. No. 90. p. 380 .

Witts, L. J. (1931). Guy's Hosp. Rep., 81, 193.

Wood, I. J., Cowling, D. C., Ungar, B., and Gray, A. (1960). Aust. Ann. Med., 9, 309.

Wynder, E. L., and Fryer, J. H. (1958). Ann. intern. Med., 49, 1106.

\title{
Aetiology of Acute Hemiplegia in Childhood
}

\author{
EDWIN R. BICKERSTAFF,* M.D., M.R.C.P.
}

[With Special Plate]

Brit. med F., 1964, 2, 82-87

"Acute infantile hemiplegia of obscure aetiology" is a clearly defined clinical syndrome, well documented and easily recognizable. This ease has perhaps been too great; for by the use of this title, which is purely descriptive, one may be misled into thinking that a firm clinical diagnosis has been made. Attempts have been made in recent years to correct this, and it has also been appreciated that the syndrome is by no means confined to infants. The tendency now is to use the term "acute hemiplegia in childhood," which has expanded the scope of the diagnosis without clarifying its nature. Unfortunately it has allowed the inclusion of a number of different conditions which have only one feature in common-their * The Midland Centre for Neurosurgery and Neurology, Smethwick.
Birmingham. capacity for producing a hemiplegia in a child. Therefore, when any investigation is undertaken, be it clinical or pathological, it is essential for a clear statement to be made of the type of syndrome under consideration and the type of case to be admitted to the investigation.

\section{Clinical Syndrome}

The essential feature of the syndrome is the sudden development of a hemiplegia in a child hitherto neurologically and cardiologically normal. This therefore excludes all cases of maldevelopment, of birth trauma, of post-natal trauma, of embolism secondary to rheumatic endocarditis or congenital heart disease, and, of course, tumours, abscesses, etc. 
As the syndrome is equally apt to affect infants and older children there is little purpose in distinguishing between them, and when dealing with older children one can be more certain that they were normal previously, and more accurate, detailed, and informative history can be obtained.

The disease presents in two main ways. In the first, the child suddenly goes into status epilepticus with high fever and deep coma. The fits may be purely unilateral, unilateral at first then becoming generalized, or apparently generalized from the onset. They do not spread to successive parts of one limb, nor to alternate sides. As soon as they cease spontaneously or are successfully controlled the pyrexia settles, the coma recovers after a few hours, but the child, though becoming alert, remains hemiplegic with or without dysphasia according to the side affected.

In the second mode of presentation the child abruptly develops a hemiplegia with or without dysphasia, and though there may be loss of consciousness it is of short duration and occurs only at the onset and without epileptic features.

In either event there is almost invariably a history of illhealth during the previous days or weeks. This may consist of a vague pyrexial illness, or of tonsillitis, a sore throat, glandular enlargement in the neck, tooth or mouth infection, or sometimes tonsillectomy. In either event, when the hemiplegia is analysed it is found to affect principally the face and arm, and recovery of the leg precedes and exceeds that of the arm. In either event there are frequently mild symptoms referable to the affected limbs or occasionally to the contralateral eye in the hours or days before the fits and hemiplegia develop. In either event the child may become subject to epilepsy some months or years later, and often to athetoid movements of the paretic limb. Children are often mentally retarded, especially if the dominant hemisphere is affected.

In neither event is there a recurrence of complete hemiplegia (except as a post-epileptic Todd's paralysis) once it is fully established, nor does a bilateral hemiplegia develop. Paralysis is maximal at onset, any change being towards recovery. The child's return to alertness far exceeds the return of power to the hemiplegic side.

Examination of the C.S.F. at the inception of the illness usually reveals no abnormality, but some days later there may be a slight rise in the cell count and protein. If contrast radiography has been carried out it has usually not been for some weeks or months after the onset. Arteriography is said to show no abnormality, but air encephalography constantly shows enlargement of the ventricle on the affected side, displacement of the ventricular system towards that side, and enlargement of the sulci. If the radiographs are studied carefully the atrophic change is seen to be most marked in the territory supplied by the middle cerebral artery, but sometimes it is also to be seen in the anterior cerebral territory, and this may occur on the " normal" side as well. The posterior part of the hemisphere is usually little affected.

\section{Aetiological Theories}

By including any condition producing hemiplegia in childhood, a wide variety of pathological processes have been suggested, ranging from polioencephalitis (Strümpell, 1884) to anoxia and oedema purely as a direct result of fits (Norman, 1962 ; Cavanagh, 1962). In fact, in the symposium on this subject held at Clevedon in 1961, 27 possible causes were listed, including widely different mechanisms such as typhus, congenital syphilis, and the delayed appearance (up to 30 months) of a congenital hemiplegia. Reviews of these aetiological factors are to be found in the excellent publication "Acute Hemiplegia in Childhood" (Little Club Clinics in Development Medicine, No. 6).

From this wealth of aetiological possibilities three pathological processes stand out as clinically reasonable, as not too uncommon, and as having some degree of histological support. These are: (a) cortical thrombophlebitis, (b) encephalitis, and (c) arterial occlusion due to thrombosis, embolism, or dissecting aneurysm. The number of patients who die in the acute stage is, however, very small and most theories are bound to rely upon the comparison of the clinical manifestations of this disease with those shown by patients, either children or adults, known to have developed one of these pathological processes. These comparisons do not always bear close examination.

\section{Cortical Thrombophlebitis}

Norman $(1953,1962)$ described cases of cortical thrombophlebitis giving a clinical syndrome similar to that under discussion, and Mitchell (1952) gave evidence to support this theory. The H.H.E. syndrome-hemiconvulsions, hemiparesis, epilepsy-of Gastaut et al. (1957) has been widely accepted as an explanation for the condition, though it is no more than another descriptive title for it. It has been suggested that the syndrome was similar to the thrombophlebitis of Bernheim (1956), but the authors themselves were not convinced of this.

However, even if it is accepted that sagittal sinus thrombosis and spread of the process to one hemisphere can produce purely a hemiplegia, and accepting that the onset of this process can be both acute and pyrexial, the similarity ceases there.

The epileptic manifestations of thrombophlebitis are usually of a "spreading" character; the paralysis when the sagittal sinus is involved is predominantly in the lower limb and least in the face; the patients either remain gravely ill for a long time or recover both consciousness and power rapidly. They commonly develop papilloedema, and though it is possible for the lesion to remain unilateral, very often there is spread to involve the opposite hemisphere as well. Careful study of the venous phase of early arteriograms shows no evidence of venous occlusion, and in the later stage there is no evidence of dilated collateral venous channels. Each case of thrombophlebitis varies slightly from the next and there is not the exact repetition of clinical and radiographic pictures seen in the childhood hemiplegia.

\section{Encephalitis}

Most clinicians will believe they have seen purely unilateral encephalitis, but this is exceedingly rare and the diagnosis often in doubt. The epileptic manifestations are usually widespread and variable in their extent and degree, changing from one side to the other. If the encephalitis is severe enough to produce profound hemiplegia the patient rarely remains alert, and the hemiplegia does not show the distribution seen in these cases. C.S.F. abnormalities are common, and not rare, at the most acute stage. Pathological evidence of encephalitis is exceedingly scanty, though Norman (1962) describes one case. Sandifer (1962) emphasized the manner in which hemiplegia may be associated with exanthemata and immunization procedures, and I have seen a striking example of a very similar syndrome with a high cell count in the C.S.F. immediately following measles. This cannot, however, account for more than a fraction of the cases.

\section{Arterial Occlusion}

Here the situation is entirely different. The abruptness of onset, the distribution of the hemiplegia, the recovery from maximal disability at onset, the alertness of the child once recovered from the post-epileptic coma-all clinically resemble arterial occlusion. The predominance of fits need not be a point against it, for the child's brain may react to any insult by 
producing fits. The main problem is to explain why any arterial lesion should develop, there being no pre-existing vascular disease, no cardiac origin for emboli, no congenital anomaly to produce haemorrhage or dissection, and, finally, no evidence of vascular occlusion arteriographically when the examination is carried out some time after the acute phase.

Despite this, however, to any clinician whose work brings him in contact with the neurology of children and of adults, one fact stands out-the great similarity of the clinical picture of this condition (fits excepted), both in its acute phase and in its subsequent course, to that seen in disease of the internal carotid artery in later life. Similar also is the type and distribution of the atrophic changes seen on air-encepinalography carried out after the acute episode. Bearing this in mind, it seemed possible that the failure to demonstrate arterial changes may have been related to the time at which the examination had taken place, to the natural reluctance to pay attention to minor abnormalities, and to the failure to compare the state of the arteries on the normal and abnormal sides.

\section{Present Investigation}

An investigation was therefore launched in 1955 aimed at the arteriographic study of cases of this syndrome, the examination being carried out at the earliest possible stage. At the same time it was intended to make careful comparison of the vessels on the normal and the abnormal sides. The paediatricians in the Birmingham Region were asked if they would refer cases of the condition to the Midland Centre for Neurosurgery and Neurology within the first few days of the illness, when bilateral carotid arteriography, by careful percutaneous puncture, was carried out immediately, either by Dr. C. P. Moxon or by Dr. Leonard Langton.

Fifteen cases were investigated during this period of eight years, the clinical picture in each corresponding to the criteria laid down earlier. Of the 15 cases five were not seen until many weeks after the onset, and in these the common finding of an apparently normal arteriogram was confirmed. Of the remaining 10 , the examination was carried out within the first few days and an arterial abnormality of some type was demonstrated in each. Illustrative case histories are here given, including those whose radiographic abnormalities most easily lend themselves to reproduction. Only abnormal physical signs are mentioned.

\section{Illustrative Case Reports}

\section{Case 1}

A girl aged 8 developed a severe sore throat, and four days later, when the throat infection had almost resolved, she experienced a sudden intense pain in the left eye. This lasted three to five minutes and cleared, but within the next 15 minutes she developed a paralysis of the right side of the face and the right arm. The weakness was maximal at onset, and after two days she began to make a steady recovery.

Examination three days after the onset revealed an upper-motorneurone weakness of the right face and arm, maximally affecting the hand. There was little if any weakness of the leg. The reflexes were exaggerated on the right side, but the plantar responses were normal. There was no speech disturbance.

Arteriography carried out on the fifth day showed striking differences on the two sides. The right side was completely normal (Special Plate, Fig. 1). On the left the carotid artery was narrow, its lumen irregular, and the first part of the middle cerebral artery showed multiple irregularities (Special Plate, Fig. 2). The first part of the left anterior cerebral artery was irregular and constricted, but the rest of the vessel filled well from the right side. Repeat of the arteriogram 10 months later showed that the calibre of the vessels had returned to normal, and only one of the irregularities remained in the left middle cerebral artery.

\section{Case 2}

A girl of 12 developed a severe upper respiratory infection which listed one week. At the end of this time she suddenly developed weakness of the right arm and the left leg. The weakness in the leg was very transient and had cleared within an hour. In two days the arm had almost returned to normal, but four days later she quite suddenly developed a complete right hemiplegia and aphasia. Again the leg rapidly improved.

On examination she had a global dysphasia with predominantly an expressive defect, and there was an upper-motor-neurone paralysis of the right side of the face and of the right arm, with slight weakness of flexion of the right leg. The reflexes on the right side were exaggerated and the right plantar was extensor.

Arteriography was carried out 10 days after the first symptoms occurred. On the left side (Special Plate, Fig. 3) the internal carotid was narrowed in its upper part, and no dye flowed beyond the bifurcation, the obstruction extending a short distance into the siphon. The arteriogram on the right side was entirely normal, and both anterior cerebral arteries filled from this side.

Air-encephalography (see Diagram), carried out three weeks later, showed enlargement of the left ventricle, very slight shift of the ventricular system towards the left, and enlargement of the left sulci.

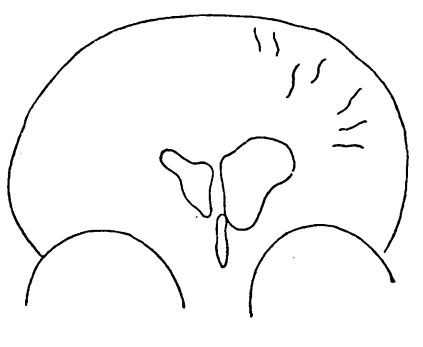

CASE 2

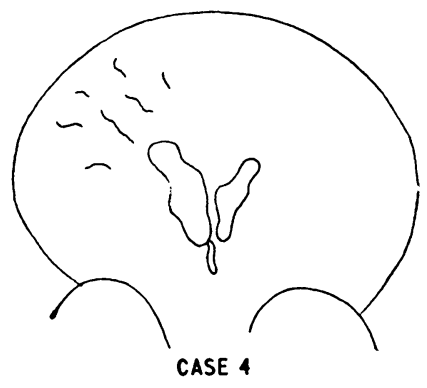

Tracing from air encephalograms.

The patient made a steady recovery, the leg returning to normal, and the dysphasia completely resolving, but there was still weakness of the right side of the face and right arm six months later.

Arteriography repeated on the left side showed return of the carotid lumen to normal size, and, though there was still partial obstruction to the intracranial portion, some dye now reached the middle cerebral vessels.

\section{Case 3}

A girl aged 5 developed severe infection of teeth, mouth, and throat, during the course of which she suddenly lost consciousness and had an epileptic fit. On recovery of consciousness she had a right hemiplegia and was aphasic. Within four hours, however, she returned to normal. Later that same day this exact sequence of events was repeated; she went into deep sleep and on waking the next day the hemiplegia and aphasia had gone. There was then an interval of three days, when these features again recurred, but on this occasion the hemiplegia and aphasia persisted.

Examination revealed a mixed expressive and receptive dysphasia, and an upper-motor-neurone paralysis of the right side of the face and of the right arm. The right leg was slightly weak, with increased reflexes.

Arteriography was carried out on the fifth day. The right carotid tree was normal throughout, and both anterior cerebral arteries filled 


\section{E. R. BICKERSTAFF: ACUTE HEMIPLEGIA IN CHILDHOOD}

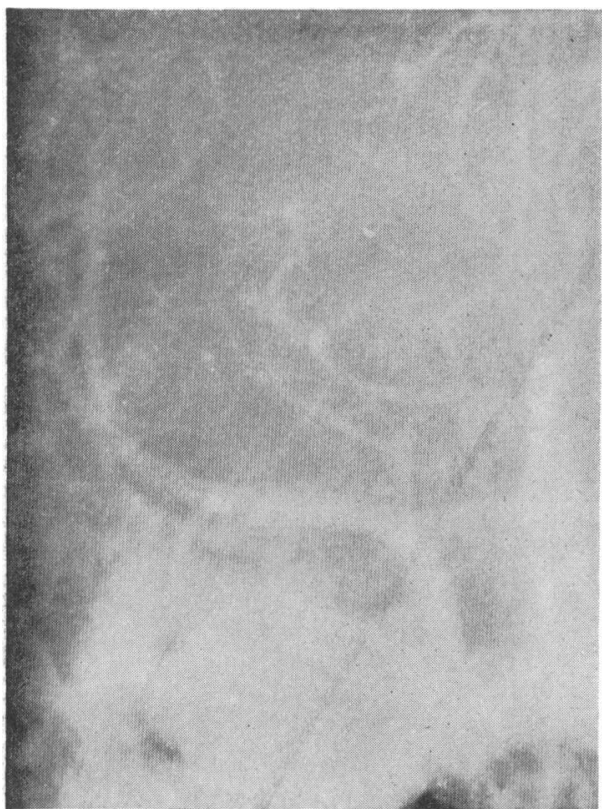

FIG. 1

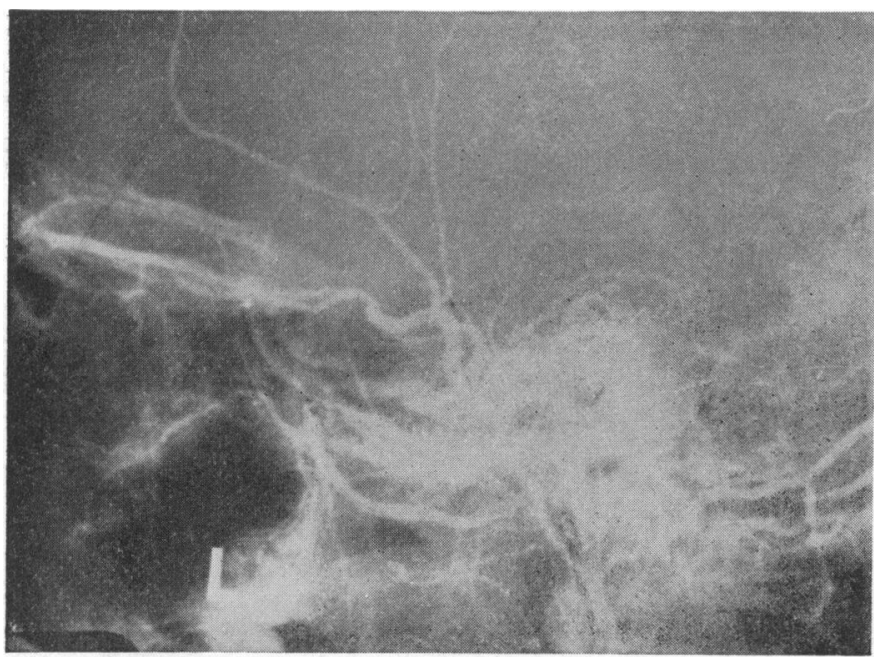

FIG. 3

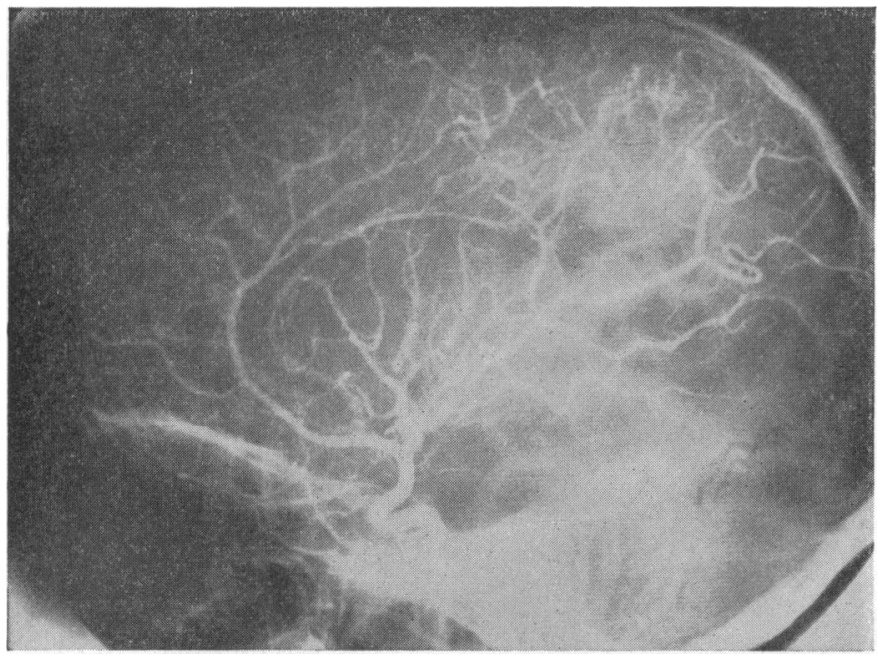

FIG. 5.-Case 3. Lateral view of left carotid arteriogram taken 12 months later than Fig. 4, showing return to normal, despite residual physical signs.
Fig. 1.-Case 1. Enlargement of normal right internal carotid arteriogram.

Fig. 2.-Case 1. Enlargement of left internal carotid arteriogram, showing reduced calibre of vessels, with marked irregularities in the first part of the middle cerebral artery, indicated by arrow.

FIG. 3.-Case 2. Lateral view of left carotid arteriogram showing narrow calibre of the vessel and obstruction in the siphon.

Fig. 4.-Case 3. Lateral view of left carotid arteriogram showing constriction and irregularity of whole carotid tree with partial filling of middle cerebral artery only.

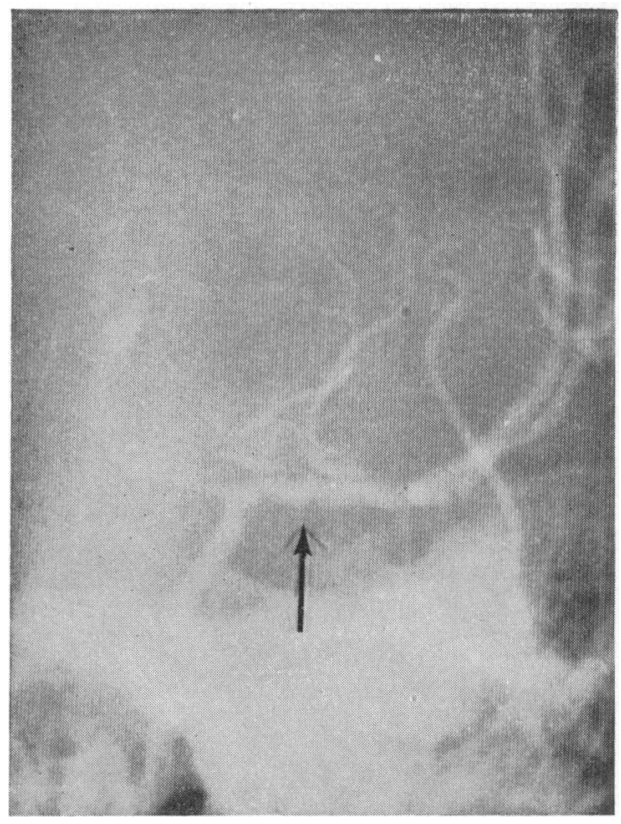

FIG. 2

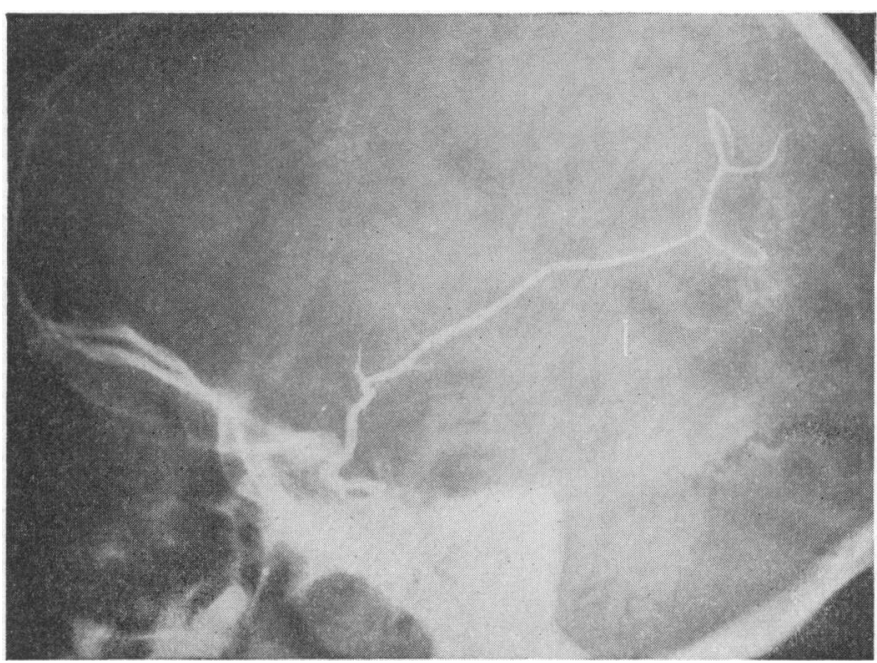

FIG. 4

FIG. 6. - Case 4

Antero - posterior

view of right carotid

arteriogram showing

constriction showing

irregularity of in-

ternal carotid and

its branches. Compare Fig. 7. 
E. R. BICKERSTAFF: ACUTE HEMIPLEGIA IN CHILDHOOD

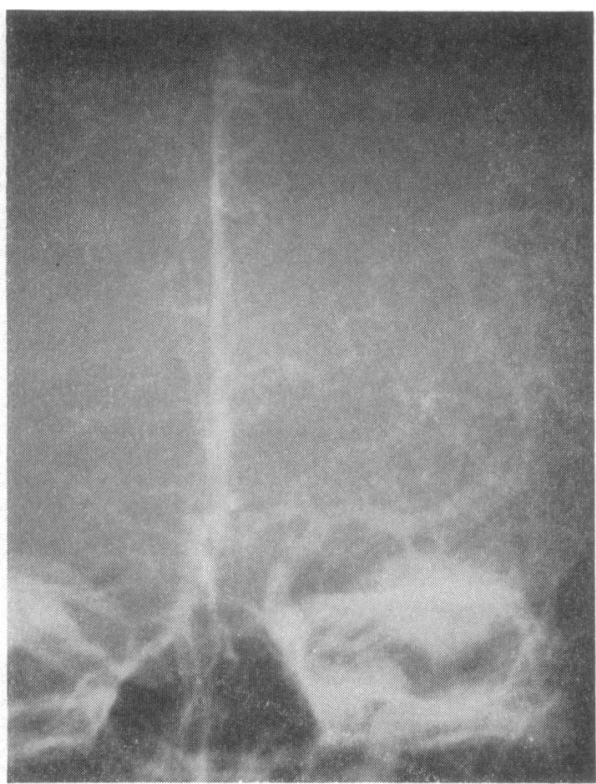

FIG. 7

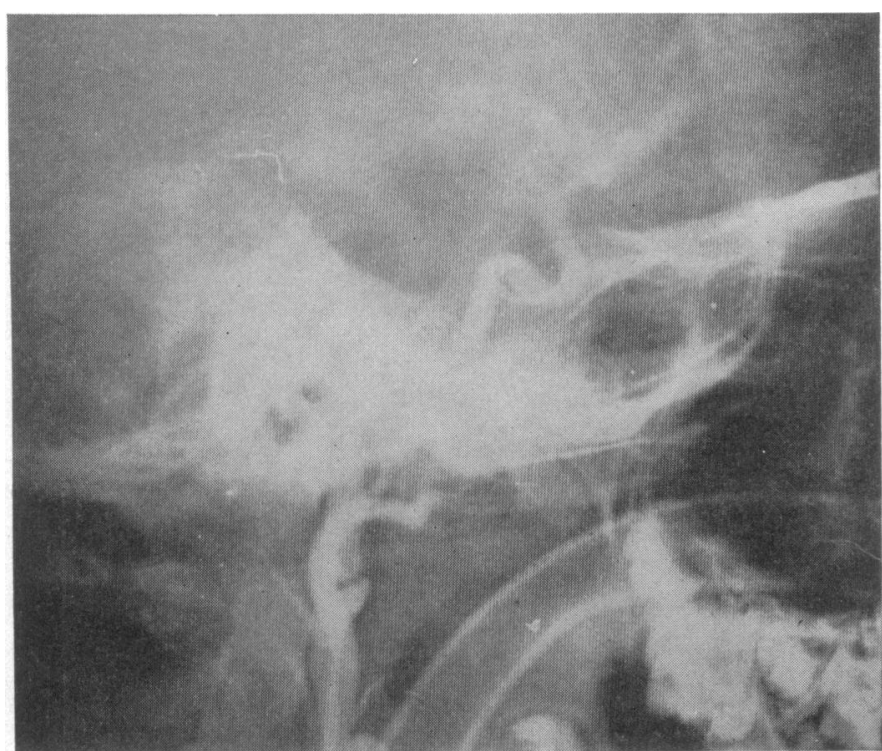

FIG. 8

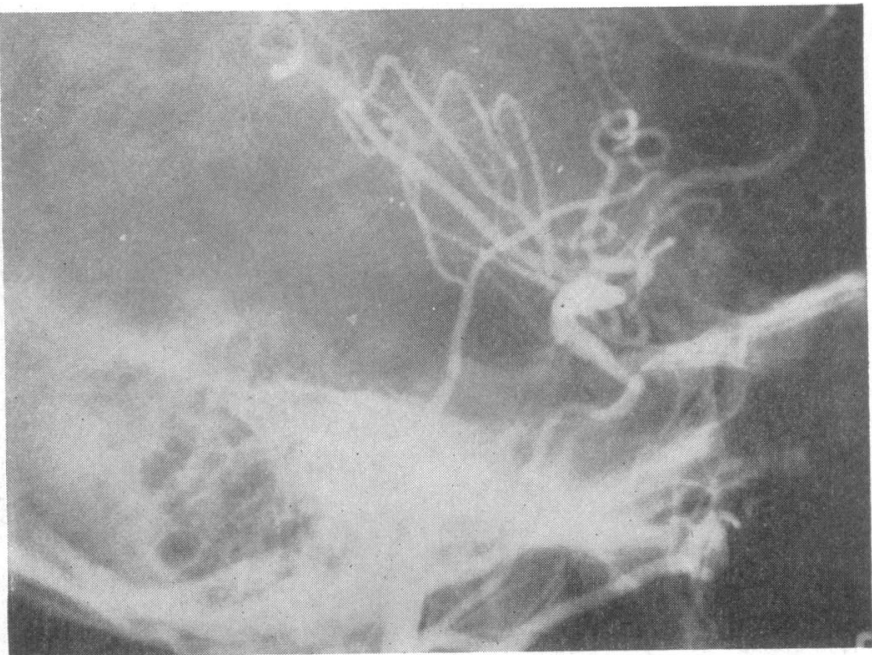

FIG. 11.-Case 8. Lateral view of right carotid arteriogram showing marked constriction of the carotid both within and below an infected cavernous sinus.
Fig. 7.-Case 4. Antero-posterior view of normal left carotid arteriogram.

Fig. 8.-Case 5. Lateral view of left carotid arteriogram showing defect in internal carotid behind tonsillar fossa. (This defect is constant in all views and is not due to looping of vessels.)

Fig. 9.-Case 5. Enlargement of antero-posterior view of left carotid arteriogram showing constriction of intracranial branches and marked irregularity of the first part of the middle cerebral artery (cf. Figs. 2 and 6 ).

Fig, 10-Case 6. Left common carotid arteriogram showing complete obstruction to the internal carotid artery in the neck.

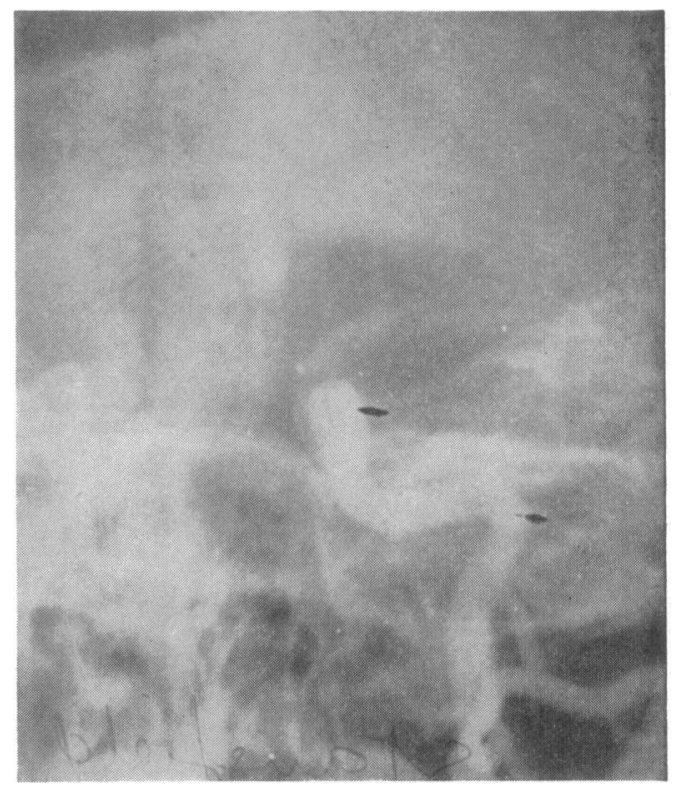

FIG. 9

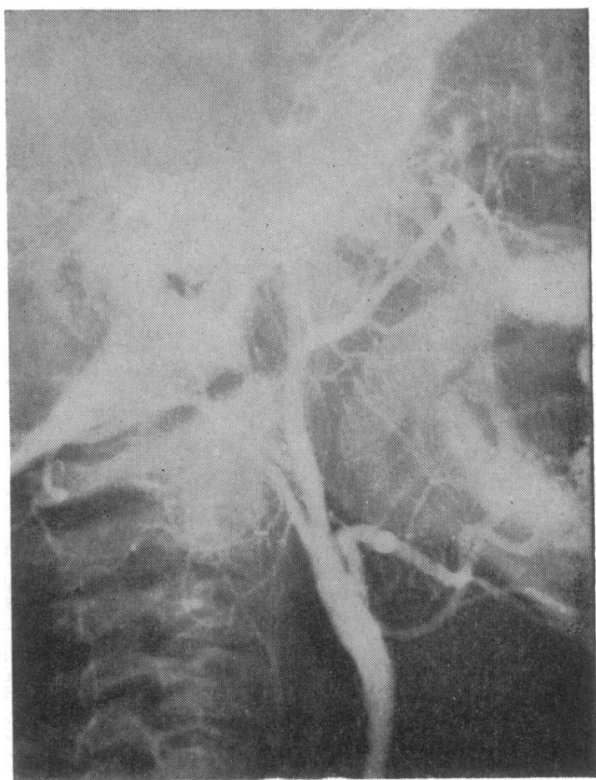

FIG. 10

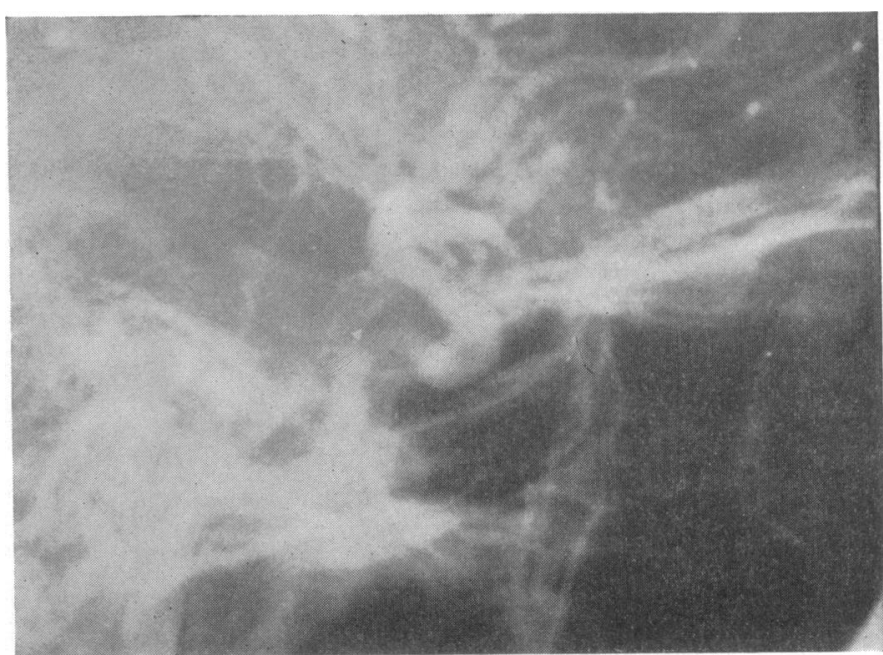

FIG. 12.-Case 8. Lateral view of right carotid arteriogram taken three months later than Fig. 11, showing return of carotid to normal. 
from this side. On the left side there was marked constriction of the carotid tree with very little filling of either the anterior or the middle cerebral tree (Special Plate, Fig. 4).

The child made a steady and excellent recovery. Twelve months later there was only a slight residual hemiparesis and some intellectual retardation, but no dysphasia. Arteriography was repeated on the left (Special Plate, Fig. 5) and showed a striking return of the vessels to normal, both anterior cerebrals now filling from this injection.

Air-encephalography showed the usual atrophic changes on the left side (see Diagram)

\section{Case 4}

(This case demonstrates the less florid abnormalities in this series, sometimes appreciated only if all the films are examined together.)

A left-handed 11-year-old girl developed a septic tonsillitis and had her tonsils removed, with considerable subsequent sepsis in the tonsillar fossa, particularly on the right. Eleven days after this she had attacks of difficulty in speaking lasting some minutes and recovering spontaneously. These recurred over seven days, when she suddenly lost consciousness, fell to the ground, regained consciousness immediately, but had a left hemiplegia with marked dysphasia.

On examination she had a predominantly expressive dysphasia, weakness of the left side of the face, profound weakness of the left arm, and weakness and increased reflexes in the left leg, with an extensor plantar.

Arteriography (Special Plate, Figs. 6 and 7) carried out one week after the onset showed the left side to be normal ; on the right the lumen of the internal carotid in the upper part of the neck and intracranially was narrowed, the wall was irregular, and there were marked irregularities in the first part of the middle cerebral, the first part of the anterior cerebral being either absent or grossly constricted.

An air-encephalogram three weeks later showed atrophic changes in the right hemisphere (see Diagram).

\section{Results of Arteriography}

Summarizing the radiological findings in ascending order of severity, they consisted of (1) irregularities of the lumen of the carotid and the first part of the middle cerebral arteries on the affected side-this would perhaps not have been noticed had the other side not been quite normal ; (2) very marked narrowing of the whole carotid tree on the affected side, later returning to normal calibre ; (3) localized narrowing of the terminal carotid and its branches; (4) actual occlusion of the terminal portion of the carotid or its branches; and (5) enlargement of the ventricle on the side of the lesion and later displacement of the ventricular system towards the affected side, with widening of the sulci both on this side and in the anterior parasagittal region on the non-affected side.

Not all these features were present in each case, but some combination of them could be found in most, if not all, of these children, if the arteriograms were carried out early enough. This corresponds with the findings of Till and Hoare (1962) and the report of Shillito (1964). Duffy et al. (1957) and Goldstein and Burgess (1958) had also reported complete carotid thrombosis producing an identical syndrome, but in isolated cases.

\section{Possible Site and Origin of the Arterial Lesion}

Interesting as they are, these findings do not explain why these children develop carotid lesions, nor which part of the carotid is primarily involved. In searching the previous history one feature repeatedly present in the days preceding the hemiplegia is an infective illness of some sort, most often a throat infection, or, as in Case 4, a recent tonsillectomy. The internal carotid artery is in close relation to the tonsillar fossa, and indeed to many of the cervical lymph nodes, including those just at the entrance to the carotid canal. If it could be shown that, in a child, lesions of the carotid which are known to originate behind the tonsillar fossa produce a clinical picture such as that under investigation, it would give support to the theory that the lesion of acute childhood hemiplegia might originate at this site. Supporting evidence of this type is obtained from the so-called "pencil injuries."

Case 5.-A 6-year-old boy was running with a stick in his mouth, when he tripped, fell forwards on to the stick, and forced it backwards into his tonsillar fossa. He became immediately dysphasic, could not stand, and then lost consciousness, probably having some form of epileptic fit. On recovery he had paralysis of the right side of the face and right arm, with a moderate expressive dysphasia. The hemiparesis resolved gradually over many months, during which he developed athetoid movements of the affected arm. An arteriogram carried out many weeks after the injury showed a constant defect in the carotid artery behind the tonsillar fossa (Special Plate, Fig. 8), with irregularities in the first part of the left middle cerebral artery and a hair-like anterior cerebral artery-comparable to Cases 1 and 4 (Special Plate, Fig. 9). Air-encephalography carried out a year later (see Diagram) showed enlargement of the ventricle on the affected side and displacement of the ventricular system to that side.

Case 6.-A boy of 4 fell forward on to a pencil which he held in his mouth, forcing this backwards and lacerating the left tonsillar fossa. There was no immediate neurological deficit, but several hours later he went into status epilepticus, and when consciousness returned he was found to have a right hemiplegia. Arteriography was carried out within 48 hours. This showed complete occlusion of the left internal carotid artery (Special Plate, Fig. 10). The child improved for three days, and then suddenly lost consciousness and died. At necropsy there was infarction of the middle cerebral territory of the left hemisphere. The internal carotid, behind the tonsillar fossa, showed a dissecting aneurysm of the wall, the clot at one point having broken into the lumen. There were some pieces of soft clot in the carotid and in the first part of the middle cerebral artery, occupying the same position as the irregularities shown in Cases 1, 4, and 5 .

These cases were almost identical to those described earlier, but here the site of the lesion is known exactly and its cause is trauma, the hemiplegia being due to peripheral embolization.

\section{Role of Infection}

If infection were to play a part in the cases under discussion it presumably would do so as a result of inflammatory changes spreading inwards from the adventitia of the vessel, so producing a local arteritis. Such infection might come direct from the tonsillar fossa or from infected glands in close proximity. If this suggestion has any basis it is necessary to show that a similar clinical and radiographic picture could occur from known local sepsis. The following two cases give strong support.

Case 7.-A woman of 40 developed a severe throat infection, after which a cervical lymph node became enlarged and suppurative. This was in close relation to the carotid bifurcation. She suddenly developed a right-sided hemiparesis and slight dysphasia, the arm and face being predominantly affected. Arteriography was carried out within five days. This showed a constriction of the whole carotid artery extending upwards from the region of the node, with marked irregularities of the lumen very similar to those shown in Cases 1 and 4.

Case 8.-A woman of 20 developed an extensive infective lesion of the cervical lymph nodes and also symptoms suggestive of an infective thrombosis of the cavernous sinus. Arteriography showed constriction and irregularity of the carotid artery below the siphon (Special Plate, Fig. 11). This extended into the neck well below the confines of the cavernous sinus itself. Arteriography was repeated three months later, by which time the patient had recovered and the calibre of the vessel had returned completely to normal (Special Plate, Fig. 12). 


\section{Discussion}

It appears from this study (a) that a lesion of the carotid artery due to trauma through the tonsillar fossa can produce a clinical and radiographic picture similar to that of idiopathic acute hemiplegia in childhood; $(b)$ that in a high proportion of children with this syndrome abnormalities of the carotid artery and/or its main branches can be demonstrated if the examination is carried out both early enough and on the two sides for purposes of comparison; and (c) that the carotid artery in relation to infected lesions can show very similar appearances. The suggestion is therefore made that many cases of acute hemiplegia in childhood are due to an inflammatory arteritis of the carotid following throat or neck gland infection. Complete occlusion of the carotid, though reported, is, however, rare, and the arteriographic appearances are more often similar to those seen when emboli have lodged at or just beyond the bifurcation into middle and anterior cerebral branches.

Emboli of fibrin or platelets could form on the diseased intima in the neck and then spread peripherally, producing irregularities in the lumen of the smaller vessels if not large enough to cause complete blockage. That irregularities of this type can be caused by mural thrombi is clearly shown in the recent book by Gunning et al. (1964). This would explain the normal late arteriograms, because by this time emboli may by fragmentation have passed through the circulation, as is known to occur in internal carotid disease of later life. It would also explain the occasional appearances of disease in the opposite anterior cerebral artery distribution-for a shower of emboli could easily reach this site if the anterior communicating artery were patent, and particularly if both anterior cerebrals prefer to fill from one side-a phenomenon well known to arteriographers. The ischaemic lesions would then be followed by atrophy and gliosis, producing ventricular enlargement and displacement, with enlargement of sulci, both on the side primarily affected and in the territory of the opposite anterior cerebral artery. Clinically this could result in fits or involuntary movements at a later date, purely as a non-specific effect.

This explanation is open to a number of criticisms. Not all the cases investigated showed carotid or other arterial lesions. Most of these were those examined late in the course of the disease. It is possible that in others the emboli may have lodged too far peripherally to show detectable arteriographic abnormalities. These might cause a relative but not absolute ischaemia, capable of good recovery provided the blood-flow remained adequate.

That one hemisphere might remain in a precarious state as regards its blood supply was suggested by the case of an adult patient who had had a typical acute childhood hemiplegia at the age of 10 . She made a very good functional recovery with only slight residual weakness of the face and arm. At the age of 29 she had a severe haematemesis from a peptic ulcer. There was an immediate return of total hemiplegia, together with equally immediate recovery on transfusion and restoration of blood-pressure.

A second criticism is that the arteriographic appearances might be due to a technical artifact. Certainly an incorrectly placed needle may send a child's carotid into spasm, and a slow injection may give a misleadingly " constricted" stream of dye. These arteriograms were, however, carried out with great care by radiologists with wide experience of the examination of children, and the position of the needle was photographed in each case. No technical difficulty was experienced in any case and the "trickle" technique was not used. The examination was carried out under general anaesthesia, when it is common experience that children's intracranial arteries are appreciably dilated rather than constricted. Bilateral arteriograms were performed in each case, and it seems too great a coincidence that if the appearances were artifactual they should have been shown only in children with this condition, and only on the side clinically suspected as being abnormal.
Even if direct invasion of the vessel by inflammatory cells is not the explanation in all cases, lesions of the intima of arteries are said by Ford and Schaffer (1927) to be common in children in a variety of infective pyrexial illnesses, and they quote Klotz (1911) as having described perivascular inflammation passing on to necrosis of the media. It is of interest, however, that the same authors have also shown a number of cases of this syndrome following diphtheria and scarlet fever, both of which are, of course, throat and tonsillar infections.

It would be foolish not to accept the fact that a syndrome of this type is likely to have more than one cause, and it is probable that most of the causes previously suggested play a part in isolated cases. It seems from these clinical studies, however, that if the times and techniques of examination described are observed an arterial occlusive lesion in some part of the carotid tree will be the most common lesion demonstrated.

The consequences of this disease can be so disastrous that when a child develops focal fits or focal paralyses during the course of a throat or neck infection, or shortly afterwards, serious consideration should be given to the use of anticoagulants. This raises many problems both of early diagnosis and of suitability for treatment. The results of the use of anticoagulants in carotid artery disease have in general been disappointing, the exception being in those cases where it appears that multiple emboli are being thrown off from the surface of an atheromatous plaque. If the aetiological theory suggested in this paper is true the situation in the earliest stages is comparable. It will be too late once the full picture has developed, which unfortunately takes place so quickly in many cases that maximal damage is done at the onset. This might perhaps be limited by the use of hypothermia, and, in cases where arteriography has shown marked oedema of the hemisphere, by intravenous hypertonic urea. In neurological and neurosurgical departments these cases are often seen too late for it to be of much value to put these measures into operation, and it has been the aim of this paper to draw the attention of paediatricians, general physicians, and general practitioners to the need for early investigation, for it might in some instances be possible to curtail a sequence of events which within a few hours changes a normal child into one who is disabled, retarded, epileptic, and athetotic.

\section{Summary}

The syndrome of acute hemiplegia in childhood is defined, and the most popular theories of aetiology are critically examined. The frequency of preceding throat infection is stressed, and attention is also drawn to similarities of the syndrome to that of internal carotid disease in later life.

Arteriography was carried out bilaterally in 15 cases, and on careful comparison of the two sides it was shown that in those cases examined sufficiently early, partial occlusion, constriction, or irregularity of the internal carotid artery and its main branches could be demonstrated on the affected side, the other being normal.

Similar appearances were found in children with traumatic lesions of the carotid artery behind the tonsillar fossa, and also in carotid arteries closely related to infected cervical glands.

It is suggested that in a high proportion of these cases there is an inflammatory carotid arteritis in the neck, with intimal damage, peripheral embolization, and cerebral lesions ranging from transient ischaemia to frank infarction. The possibilities for prevention of disability are briefly discussed.

I am most grateful to the paediatricians in the Birmingham Region who made this study possible by referring cases under their care ; to my radiological colleagues, Dr. C. P. Moxon and Dr. L. Langton, for their painstaking arteriographic technique ; and to my colleagues, Mr. J. M. Small, Mr. J. G. Hamilton, Dr. I. A. Guest, and Dr. G. S. Hall, who gave me permission to include the cases under their care. 
REFERENCES

Bernheim, M. (1956). Ann. Pédiat., 187, 153.

Cavanagh, J. B. (1962). Little Club Clinics in Developmental Medicine, No. 6, p. 49.

Duffy, P. E., Portnoy, B., Mauro, J., and Wehrle, P. F. (1957). Neurology (Minneap.), 7, 664.

Ford, F. R., and Schaffer, A. J. (1927). Arch. Neurol. Psychiat. (Chic.), 18, 323 .

Gastaut, H., Vigoroux, M., Trevisan, C., and Regis, H. (1957). Rev. neurol., 97, 37.

Goldstein, S. L., and Burgess, J. P. (1958). Amer. f. Dis. Child., 95, 538 .
Gunning, A. J., Pickering, G. W., Robb-Smith, A. H. T., and Ross Russell, R.' (1964). Quart. F. Med., 33, 155 .

Klotz (1911). Quoted by Ford and Schaffer (1927).

Mitchell, R. G. (1952). Arch. Dis. Childh., 27, 95.

Norman, R. M. (1953). Proc. roy. Soc. Med., 46, 627

- (1962). Little Club Clinics in Developmental Medicine, No. 6, p. 37.

Sandifer, P. (1962). Ibid, No. 6, p. 17

Shillito, J. (1964). F. Neurol. Neurosurg. Psychiat., 26, 559.

Shillito, J. (1964). ₹. Neurol. Neurosurg. Psychiat.,

Strümpell, A. (1884). Dtsch. med. W schr., 10, 714.

Till, K., and Hoare, R. D. (1962). Little Club Clinics in Developmental Medicine, No. 6, p. 69.

\title{
Homozygous Sickle-cell Anaemia Arising from Two Different Haemoglobins $S$
}

\author{
Interaction of Haemoglobins S and Stanleyville-II
}

\author{
MARY HALL-CRAGGS,* M.B., B.S. ; P. D. MARSDEN,* M.B., M.R.C.P., M.R.C.P.ED. ; \\ A. B. RAPER, $\dagger$ M.D., M.R.C.P. ; H. LEHMANN, $\ddagger$ M.D., SC.D., F.R.C.P. ; D. BEALE, $\ddagger$ B.SC.
}

[With Special Plate]

Brit. med. F., 1964, 2, 87-89

It is established that human adult haemoglobin ( $\mathrm{Hb} \mathrm{A}$ ) consists of $\alpha$ and $\beta$ polypeptide chains, and that each individual inherits genes determining the nature of these chains from both parents. There exist numerous variants of each type of chain, resulting in a large variety of mutants of $\mathrm{Hb} \mathrm{A}$. Many of them are rare and have a limited geographical distribution, and thus, although many combinations of abnormal haemoglobins are possible, only a few have been found, and combinations involving one abnormal $\alpha$-chain and one abnormal $\beta$-chain are particularly rare. It is these latter combinations (Smith and Torbert, 1958 ; Atwater, Schwartz, and Tocantins, 1960 ; Raper, Gammack, Huehns, and Shooter, 1960 ; Baglioni and Ingram, 1961; McCurdy, Pearson, and Gerald, 1961; Weatherall, Sigler, and Baglioni, 1962) that throw the greatest light on the genetics of haemoglobin production, and are the best evidence for the validity of the current genetic theory. There exist in the region of the Upper Nile at least three haemoglobin variants: sickle-cell haemoglobin ( $\mathrm{Hb} \mathrm{S}$ ), which is common (Lehmann and Raper, 1949), and Hbs Stanleyville-I and -II (Sta-I and Sta-II) (Dherte, Vandepitte, Ager, and Lehmann, 1959), which are rare. This report deals with a family in which the genes for both $\mathrm{Hb} S$ and $\mathrm{Hb}$ Sta-II are segregating.

\section{Case History}

The propositus was a male child of parents belonging to the Ulur tribe from the West Nile region of Uganda. He was first seen in 1961 at the age of 1 year, and until the age of 21 years he regularly attended the sickle-cell anaemia clinic at Mulago Hospital, Kampala. During this period he presented all the features of classical sickle-cell anaemia; a haemolytic crisis occurred during the first week of observation, and during the next four months he suffered from typical sicklaemic "dactylitis" of the hands and feet on several occasions; he also

\footnotetext{
* Sickle-cell Anaemia Clinic, Mulago Hospital, Kampala, Uganda. † Royal Infirmary, Bristol.

$¥$ M.R.C. Abnormal Haemoglobin Research Unit, University Department of Biochemistry, and Addenbrooke's Hospital, Cambridge.
}

had splenomegaly and occasional jaundice. The haemoglobin level ranged from 4.1 to $10 \mathrm{~g} . / 100 \mathrm{ml}$. and the reticulocyte count from 3 to $40 \%$. The appearance of the blood films was regarded as that of sickle-cell anaemia, and on electrophoretic analysis of the haemolysate only $\mathrm{Hbs} \mathrm{S}$ and $\mathrm{F}$ were noted.

In 1963 , at the age of 3 years, the child was examined again. On this occasion his blood contained $10 \% \mathrm{Hb} \mathrm{F}$, but on electrophoresis his haemoglobin was noticed to consist of three components- $\mathrm{Hb} \mathrm{F}, \mathrm{Hb} \mathrm{S}$, and a third band of slow mobility occupying approximately the position of $\mathrm{Hb} \mathrm{E}$. It was clear that the child could not be a classical sickle-cell homozygote, although he still presented the clinical and haematological picture of sickle-cell anaemia.

Fortunately the parents were available for examination on this occasion. Neither of them were anaemic, and their blood films were normal. Both exhibited sickling, and the father's haemoglobin showed the characteristic pattern on electrophoresis of the sickle-cell trait. The mother's haemoglobin, however, separated on electrophoresis into three bands, in the respective positions of $\mathrm{Hb} \mathrm{A}, \mathrm{Hb} \mathrm{S}$, and the same slow component that the child had shown. The middle band, in the $\mathrm{Hb} S$ position, was more prominent than the other two (Special Plate, Fig. 1).

\section{Family History}

On examination of the results from the mother it was possible to suggest that she had inherited two abnormal haemoglobin genes: one for $\mathrm{Hb} \mathrm{S}$ (a $\beta$-chain variant) and the other for an $\alpha$-chain variant of the same mobility-perhaps, for example, $\mathrm{Hb} \mathrm{D}_{\alpha}$. These two would occupy the same position electrophoretically, accounting for the prominent middle band observed. A person of this genetic constitution would, moreover, also form $\mathrm{Hb} \mathrm{A}$ and a hybrid haemoglobin molecule containing both the abnormal $\alpha_{2}$ and $\beta_{2}$ sub-units; and thus the three components observed could be accounted for.

To confirm this hypothesis it was necessary to examine more members of the family, and one of us was able to assemble 20 